\title{
The best of all possible coexistence
}

\author{
Mikael Fortelius $^{1,2}$ (D) Peter Myrdal $^{3}$ (D) $\cdot$ Indre Zliobaite $^{4,2}$ (D)
}

Received: 7 March 2020 / Revised: 11 July 2020 / Accepted: 30 September 2020 / Published online: 16 January 2021

(C) The Author(s) 2020

\begin{abstract}
The writings of Gottfried Wilhelm Leibniz (1646-1716) provide a window on early evolutionary thinking of a kind interestingly different from the roots of modern evolutionary theory as it emerged in the years following the French Revolution. Here we relate aspects of Leibniz's thinking to methods of modern palaeoecology and show that, despite a different terminology and a different hierarchic focus, Leibniz emerges as a strikingly modern theoretician, who viewed the living world as dynamic and capable of adaptive change. The coexistence approach of palaeoecological reconstruction, developed by Volker Mosbrugger and collaborators, with its core assumption of harmoniously co-adapted communities with strong historical legacy, represents, in a positive sense, a more Leibnizian view than functionally based and theoretically history-free approaches, such as ecometrics. Recalling Leibniz's thinking helps to highlight how palaeoecological reconstruction is about much more than reliably establishing the ecological and climatic situation of a given fossil locality. While reliable reconstructions of past conditions are certainly of great value in research, it is arguably the need to think deeply about how the living world really works that keeps palaeoecological reconstruction such a long-running and central aspect of evolutionary science. And while we struggle to understand the coexistence and dynamic interaction of endless levels of living agents of the living world, simultaneously large and small, global and local, the coexistence approach of palaeoecological reconstruction remains both an outstandingly operational method and part of a philosophical tradition reaching back to the very earliest evolutionary thinking.
\end{abstract}

Keywords Leibniz $\cdot$ The best of all possible worlds $\cdot$ Palaeoecology $\cdot$ Coexistence $\cdot$ Ecometrics

\section{Introduction}

The core effort of palaeontology, ever since its emergence in the birth throes of the French Revolution, has arguably been the reconstruction of extinct organisms and their living environments, famously and masterfully introduced by George Cuvier (Rudwick 1976). Perhaps reflecting the chaotic conditions of its birth date, Cuvierian palaeontology saw the world

This article is a contribution to the special issue "Palaeobotanical contributions in honour of Volker Mosbrugger".

Indre Zliobaite

indre.zliobaite@helsinki.fi

1 Department of Geosciences and Geography, University of Helsinki, Helsinki, Finland

2 Finnish Museum of Natural History (LUOMUS), Helsinki, Finland

3 Turku Institute for Advanced Studies (TIAS) and Department of Philosophy, Contemporary History, and Political History, University of Turku, Turku, Finland

4 Department of Computer Science, University of Helsinki, Helsinki, Finland as essentially static, with different states of existence separated by abrupt revolutions. In this it critically differs from the gradational transformism of contemporaries such as Lamarck and from the evolutionary palaeontology that was to evolve in of later decades. Reconstruction of bygone organisms and environments nonetheless remains an activity at the centre of the discipline today, and much of the basic business involved remains similar in principle. Perhaps this is inevitable: even when the main objective is to document and understand change one needs a solid grasp of what was there, before, during, and after.

As Cuvier critically realised, satisfactory reconstruction requires understanding the rules that determine how organisms relate to the demands posed by their environments. This basic requirement enabled Cuvier's spectacular successes and still underlies current methodologies of reconstruction, both of the organisms themselves and, by something akin to reverse engineering, of environments as deduced from the functional traits or environmental tolerance of their inhabitants. The latter approaches are of two kinds: reconstruction methodologies based on physical characteristics of inhabitants (Wolfe 1995; Fortelius et al. 2002; Spicer et al. 2009; Liu et al. 2012; Barr 
2017) and methodologies based on connecting coexisting fossil taxa with their nearest living relatives (Mosbrugger and Utescher 1997; Mosbrugger 2009). All such methods rely to a greater or lesser extent on the principle of actualism postulating that the processes that formed the biota of the past were similar in kind to the processes that can be observed in nature today (Rudwick 1976). From this, it is but a short step to the assumption that the relationships between biota and environments are at some sort of dynamic equilibrium, maintained by processes of adaptive evolution. And the step from such a view to some pragmatic concept of dynamic optimisation is also short.

It is common to make jocular reference to the German enlightenment philosopher Gottfried Wilhelm Leibniz's concept of the best of all possible worlds (or, as it might be, islands, or wheels, or friends, or even teeth (Evans and Sanson 2003)), but for most non-specialists, the reality of Leibniz's true thoughts and intentions remain buried under the alluvium of scorn poured on him by Voltaire in his satirical novel Candide (Voltaire 1759). And even if his true target may have been his contemporary antagonist and competitor Pierre-Louis Moreau de Maupertuis rather than Leibniz, who by then had been dead for 40 years (Ekeland 2000), Voltaire's parodical depiction of Leibniz as Dr. Pangloss has prevailed. In chapter one, Dr. Pangloss explains to the naive Candide:

It is demonstrable that things cannot be otherwise than as they are; for as all things have been created for some end, they must necessarily be created for the best end. Observe, for instance, the nose is formed for spectacles, therefore we wear spectacles. (Voltaire 1759).

We intuitively understand that Dr. Pangloss' explanation has the causality reversed - in real life, spectacles are formed for the nose; therefore, we wear spectacles. The learned doctor's reasoning was only associative but not causal. Associative approaches to palaeoecological reconstruction, such as nearest-living-relative-based coexistence, will work if the world is static or changing only very slowly. Functional or causal approaches should work even when the world is changing and becomes particularly useful when it is changing more rapidly. Even in the evolutionary framework of modern palaeobiology, a tension remains between the associative and the functional interpretations of actualism (Galbrun et al. 2018).

Today the choice between taxonomic and trait-based approaches to palaeoecological reconstruction is often seen as a pragmatic matter of convenience, but in principle, there is more at stake here than how accurately a particular approach works - or does not work. Fundamentally, it is about the nature of the living world and even about the coherence of the eco-evolutionary world view. How much inertia is there in the system? How heritable is the ecological niche? How much historical legacy must be accounted for in attempts to model and forecast ecological change (Conradi et al. 2020)? As Cuvier might have asked, if the world is functionally perfect, why would it change at all? Leibniz, perhaps unexpectedly, offers an integrative perspective and explanation. Indeed, upon removal of the Panglossian cloak, Leibniz is revealed as a sophisticated thinker who foreshadowed a wide spectrum of scientific developments, not least in the field of evolutionary biology. Here we review Leibniz's theoretical connections to some current strands of palaeoecological thought and methodology, especially as they pertain to palaeoecological reconstruction.

\section{Harmony and integrity of function}

Animal function, as it might be of teeth, has typically been thought of as something that would be optimised at the level of the individual. The British philosopher Charleton, a contemporary of Leibniz and known to him, is recorded by Samuel Pepys as claiming, on the 28th of July 1666 (shortly before the great fire of London), the ability to tell the natural diet of any animal from its teeth and suggesting that "man's, it is plain, was not for flesh but for fruit" (Latham 1985, 645). Yet it is surprisingly difficult to make a clear dichotomy between an individual and a working ensemble here. Although it might at first sight seem that the individual part or trait is optimised, it is actually always some level of a system. Cuvier himself developed the theoretical framework known as "the correlation of parts", encapsulating the idea that every part of an organism is perfectly designed for its function and missing parts can in principle be deduced, or even computed, from known ones, as in Newtonian mechanics (Rudwick 1976). And, as it turns out, this was already foreshadowed by Leibniz, whose "animal economy" associates with the relation between organs and function coordinated in a living system (Smith 2011, 62). For him, the system is not closed, and the animal body results from infinitely many soul-like substances, where the idea of soul-likeness picks up on the traditional Aristotelian notion of soul as a principle of life (Leibniz 1875-90, VI 540/Leibniz 1989a, 587) or what Leibniz, again drawing on Aristotelian terminology, calls "entelechy” (Leibniz 1875-90, IV 478/Leibniz 1989b, 139). Indeed, in his Monadology (1714), Leibniz famously explains that a substance or monad is "the entelechy or soul" of an "organised" or "organic" body together with which it "constitutes what may be called a living being" (Leibniz 1875-90, 617-8/Leibniz 1989b, 221). ${ }^{1}$ While a living body has what Leibniz calls "a dominant entelechy" - its principle of lifeits body is further constituted by an infinity of other living

\footnotetext{
${ }^{1}$ For present purposes, we set aside the vexed issue of the ontological status of bodies in Leibniz. For diverging interpretations, see, e.g. Rutherford 1995; Phemister 2005; Smith 2011.
} 
beings: "the limbs of this living body are full of other living beings, plants, animals, each of which also has its entelechy, or its dominant soul" (Leibniz 1875-90, VI 619/Leibniz 1989b, 222).

This relative and infinite systems perspective closely links to key concepts in evolutionary biology. Darwin's famous metaphor of the wedges (dropped for unknown reasons from the Origin after the second edition) is very much in the same spirit: "The face of Nature may be compared to a yielding surface, with ten thousand sharp wedges packed close together and driven inwards by incessant blows, sometimes one wedge being struck, and then another with greater force" (Darwin 1859, 67). For Leibniz, too, the world is primarily optimised at the system level - indeed, this seems to be the import of his notorious claim that this is the best of all possible worlds. In fact, it could be argued that the entire universe, for Leibniz, is fundamentally to be understood as one large biosphere, given the way in which living things are metaphysically basic. ${ }^{2}$

Leibniz's understanding of species of course differs importantly from the Darwinian one. It is well known that the scientific revolution was associated with a critical attitude to an Aristotelian view of species essences as fundamental organising principles in the universe. In the early development of evolutionary thinking, some, like Lamarck or perhaps Erasmus Darwin, saw species as only human abstractions on a continuous chain of transformation, while others, like Geoffroy, instead emphasised transformation by sudden leaps (saltations). For such early evolutionists, there was no place for extinction as we know it. Either the world flows on without distinctive breaks, and the coming and going of species are to some extent a matter of how we divide up the flow, or saltational change simply adds to the existing diversity. Interestingly, the person who brought extinction into palaeontological focus was Cuvier, who explicitly denied the possibility of transformation of species.

Leibniz, who precedes these thinkers in time, holds a more complex position. Justin Smith, a leading scholar on Leibniz, has recently argued that rather than rejecting their reality, Leibniz reconceives species in terms of origin so that an individual's species membership is determined by shared ancestry (Smith 2011, 246). This idea is closely linked to the fact that while Leibniz denies the extinction of species, he sees species as capable of evolving: "For species can be greatly changed by the span of time, as by the interval of space, as is well witnessed by the differences between our animals and those of America" (quoted by Smith 2011, 256). At the same time, Leibniz also countenances the possibility of individuals evolving from one species to another, an idea at least in part motivated by his conception of substance as indestructible (see,

\footnotetext{
${ }^{2}$ This does not imply that we need to consider the universe as a single entity (which Leibniz denied). Cf. our remark below about the ontological status of biotic communities.
}

e.g. Leibniz 1875-90, VI 619/Leibniz 1989b, 222). However more exactly these different ideas are supposed to hang together, what is important for our purposes is the way in which Leibniz's somewhat peculiar views on evolution at the level of species as well as individuals indicate the dynamism at the centre of his thought. The relevance of his philosophy to contemporary evolutionary theory lies, in our view, not so much in the details of his conception of species as in his view of the optimisation of the global order as dynamic.

Not only is Leibniz's world dynamic but also integrated and complete at any point in time; it is capable of becoming better through change or alternative integration of its parts as "the different parts variously exchange perfection between themselves" (Leibniz 1948, 95/Leibniz 2006, 196). This combination of integrated dynamics and completeness allows many variants of coexistence to be viable. Leibniz's world, accordingly, is always in harmony. In some ways, this resembles balance in game design, where rules are tuned such that any strategy can win, no strategy is superior, and yet there are no components that are ineffective. An unbalanced system would represent wasted developmental resources and would imply existence of a static optimum. Instead, Leibniz world is in harmony as it is and yet leaves open possibilities for evolution.

This balanced, non-wasteful world connects to the (somewhat mysterious) principle of least action known from seventeenth century physics (Feynman 1942; Ekeland 2000), a principle that has its background in Leibniz's work on optics (McDonough 2018). The solution requires finding the path that has the least value, the least investment of energy perhaps. How is it possible to find the most energy-efficient path and yet preserve harmony? Wouldn't no change be the most efficient use of energy, especially if the world is already perfect at any given time? And how do we even tell, except in the longest retrospect, whether a change is for the better or for the worse? "Afflictions that are bad in the short run", Leibniz explains in his On the Ultimate Origination of Things, "are good in their effect, since they constitute a short path to greater perfection", adding that "this is what you might call stepping back in order to leap forward with greater force (one retreats the better to leap forward)" (Leibniz 1875-90, VII 307-8/Leibniz $1989 \mathrm{~b}, 154)$. Would the principle of least action allow afflictions?

Such questions are very much a matter of perspective. For Cuvier, thinking of perfectly fine-tuned animals, the only conceivable change was degeneration, change for the worse. Conversely, such fine-tuning would necessarily suffer if the organism stays the same but the environment changes. From this perspective, Leibniz appears to have been ahead of his time in postulating that the world is created by God such that, 
in virtue of the natures of its components, it accommodates the greatest variety of beings (Rutherford 1995, 30). ${ }^{3}$ As such, Leibniz's conception of the world seems to be in line with key aspects of contemporary theories of self-organising systems, according to which the resulting organisation is wholly decentralised, distributed over the components of the system, while the rules specifying interactions among the system's components are executed using only local information (Camazine et al. 2003).

There is a hierarchy of system levels here, and things may appear different depending on the level observed. Individuals, species, populations, communities, ecosystems, and the biosphere - all represents potential targets for optimisationgiven appropriate processes and under whatever constraints may apply. For Leibniz, apparently adverse effects ("afflictions") at lower levels were there in order to improve optimisation at higher levels, as he explains using the analogy with a painting:

Look at a very beautiful picture, and cover it up except for some small part. What will it look like but some confused combination of colors, without delight, without art; indeed the more closely we examine it the more it will look that way. But as soon as the covering is removed, and you see the whole surface from an appropriate place, you will understand that what looked like accidental splotches on the canvas were made with consummate skill by the creator of the work. (Leibniz 1875 90, VII 306/Leibniz 1989b, 153).

This benign view of adversity, famously ridiculed by Voltaire, somewhat foreshadows Charles Darwin's view that, despite all the suffering necessary for natural selection to work, there is still more happiness than suffering in the world (Darwin 1958). This idea remains characteristic of evolutionary thinking today: populations adapt through differential reproductive success of their members and the evolution of populations, in turn, has cascading effects at the levels of species, communities, and above.

The fact that Darwin focused at the species level while Leibniz was primarily concerned with the "world" hides considerable convergence in their thinking, including also the shared view that constraints on change are intrinsic to the system, rather than extrinsically imposed limits. Such a system-based perspective on function is inevitably dynamic: rather than optimise everything, you optimise some parts at the cost of others. In contrast to Voltaire's parody, the best of all possible worlds was not a tautology, nor was it static. Leibniz and Darwin

\footnotetext{
${ }^{3}$ We do not here wish to take a stand on the interpretive question of whether the idea of optimisation is in tension with his claim that the actual world maximises perfection (see, e.g. Rutherford 1995 and Roinila 2007).
}

shared a dynamic view of the world as an interconnected system, which contrasts sharply with the static version of Cuvierian correlation of parts, where the only possible result of change is disharmony and deterioration of function. Despite important differences between Leibniz's conception of species and the Darwinian one, he appears, at a more general level, to accommodate what today we would call adaptive evolution, capable of tracking a changing world and, in doing so, causing further change in turn.

\section{The queen and the anarchist}

Leibniz thought, as did Lamarck, that climatic and environmental influence can alter traits within members of a species (Smith 2011, 264). Superficially this seems to contradict Darwin's emphasis on competition as the main propeller of evolution, but upon closer scrutiny, the views converge to a surprising degree.

Darwin's ten thousand wedges metaphor for the competition between species was cited above: when one wedge is driven inwards, the others have to pop out. Van Valen (1973) rephrased this principle as the Red Queen's hypothesis: “a change in the realised absolute fitness of one species is balanced by an equal and opposite net change in the realized absolute fitness of all interacting species considered together." One strand in Leibniz's thought clearly seems to resonate with this modern idea: "If the perfection of the world remains the same, some substances cannot continually increase in perfection without others continually decreasing in perfection" (Leibniz 2006, 196). For Leibniz, the best possible world was a dynamic one that allowed individuals to develop via continuous exchange. To use a word common in modern evolutionary literature, it is a world of tradeoffs, even a world to be understood as a zero sum game, as it was implicitly for Darwin and explicitly for Van Valen (1980).

Yet in Leibniz we also find another strand, according to which the perfection of the world, rather than being constant, is increasing: "we must also recognise a certain constant and unbounded progress in the whole universe, so that it always proceeds to better greater development (cultus)" (Leibniz 1875-90, VII 308/Leibniz 1989b, 154; see Rutherford 1995, 52). Indeed, this would be part of what makes this world the best possible (Leibniz 1948, 95/Leibniz 2006, 198). The emphasis on progress is, for Leibniz, closely connected to the idea that an individual's perfection lies in her contribution to the "common good" (Leibniz 1875-90, VII 307/Leibniz 1989b, 154). In this respect, Leibniz's conception of the evolution of the world seems to depart from what has widely been 
seen as the main mechanism of natural selection. Instead, he would seem to be on the side of the famous Russian anarchist count Petr Kropotkin, who emphasised cooperation and held that mutual aid (symbiosis by a modern name) is prevalent in the living world (Kropotkin 1902). "Horses and deer unite to protect each from their foe, wolves and lions gather to hunt, while bees and ants work together in many different ways. Kropotkin said that mutual support is an established fact within the feathered world, with eagles, pelicans, vultures, sparrows, and other fowl, collectively searching for and sharing food. Some species of birds even gather together at the end of the day to sleep" (Mason 2019).

Far from eccentric, the view that symbiosis and positive coevolution are important factors in biological evolution (Margulis and Fester 1991) has been gaining considerable currency in recent decades. The concepts of niche construction (Matthews et al. 2014) and holobiont (Gilbert and Tauber 2016) are recent additions to the list of evolutionary concepts that reverberate with a Leibnizian sense of a world both integrated and complete, yet capable of improvement through change or alternative integration of its parts. Instead of viewing ecosystems as sets of fiercely competing individuals and species, ecosystems are here seen more as integrated teams, where the participants at all levels, including the intra-individual, collaborate for shared system-level benefit and compete with other such teams. The trendy concept of the gut biome will be a familiar example of an ecosystem within an individual. The living world appears as endless levels of components, living agents, simultaneously large and small, global and local. The mechanism of perfection is recursive, as with fractals, where you zoom in on a small part only to find that it looks like the whole world.

Whether this new emphasis on collaboration will serve to tilt the balance in the age-old (and perhaps ultimately unresolvable) question of whether biotic communities are integrated entities in their own right, more than the sum of their constituent species, or just assemblages of independently occurring species, remains to be seen.

\section{The ghost of coexistence past}

This finally brings us to the coexistence approach (Mosbrugger and Utescher 1997; Mosbrugger 2009). Coexistence belongs to the class of approaches that reason about the past via their nearest living relatives. The approach goes back to Oswald von Heer (as referred in Mosbrugger 2009), who was Darwin's correspondent and critic. In a treatise on the fossil flora of Switzerland, Heer reasoned about the past climate of Switzerland via the current distribution of the nearest living relatives of the fossil plant species. Similar approaches were later used widely in palaeoecology and especially palaeoclimatology, both aquatic and terrestrial, and were, until the discovery of stable isotope geochemistry, probably the main source of information about conditions in the more recent geological past.

The principle behind the method is to assume that the climatic or ecological characteristics of a fossil taxon are similar to those of its nearest living relative. Typically, assemblages of present-day taxa are constructed to match real fossil communities, whose environments are reconstructed from overlaps of known climatic tolerances of the modern species. The key requirement for this to work is that the world changes at most reasonably slowly. At the core of the coexistence approach, we find the assumption of harmoniously coadapted communities with strong historical legacy. In this respect, the approach can then be said to represent, in a positive sense, a more Leibnizian view than functionally based and theoretically history-free approaches, such as ecometrics. As we have seen, Leibniz's world is - to put it in contemporary terms - self-organising in a way that maximises harmony and minimises energy expenditure. Its perfection is dynamic, integrated over time, and hence the best possible.

In the case of the coexistence approach, the constructed assemblages are of course only shadows or projections of the real communities that once existed. Here we find an intriguing connection to Leibniz, who seems to suggest that the world itself is an assemblage of perspectives or projections. He writes in section 57 of the Monadology:

Et comme une même ville regardée de differens cotés paroist toute autre et est comme multipliée perspectivement, il arrive de même, que par la multitude infinie des substances simples, il y a comme autant de differens univers, qui ne sont pourtant que les perspectives d'un seul selon les differens points de veue de chaque Monade. (Leibniz 187590 , VI 616$)^{4}$

Might we posit the best of all possible coexistence as one such perspective on the best of all possible worlds as we understand it here, the dynamic interaction of endless levels of living agents, simultaneously large and small, global and local? Might that even be the fundamental entity that we struggle to capture with the concept of community evolution? These are deep questions, unanswerable perhaps, but meanwhile the coexistence approach remains a delightfully Leibnizian window on communities and conditions of the past and a mainstay of palaeoecology as we know it today.

\footnotetext{
4 "Just as the same city viewed from different directions appears entirely different and, as it were, multiplied perspectively, in just the same way it happens that, because of the infinite multitude of simple substances, there are, as it were, just as many universes, which are, nevertheless, only perspectives on a single one, corresponding to the different points of view of each monad" (Leibniz 1989b, 220).
} 
Acknowledgements This is a contribution to the special issue in honour of Volker Mosbrugger. We thank Elsa Fromond and Lilli Alanen for introducing the authors to each other, William Bausman for recommending Smith (2011), and Carl Fortelius for pointing us to Ekeland (2000). We thank two anonymous reviewers for their comments. We are also grateful for the invitation to contribute to this special issue by the guest-editors Angela Bruch, Dieter Uhl, and Torsten Utescher. This is a contribution from the Valio Armas Korvenkontio Unit of Dental Anatomy in relation to Evolutionary Theory.

Funding Open access funding provided by University of Helsinki including Helsinki University Central Hospital.

\section{Compliance with ethical standards}

Conflict of interest The authors declare that they have no conflict of interest.

Open Access This article is licensed under a Creative Commons Attribution 4.0 International License, which permits use, sharing, adaptation, distribution and reproduction in any medium or format, as long as you give appropriate credit to the original author(s) and the source, provide a link to the Creative Commons licence, and indicate if changes were made. The images or other third party material in this article are included in the article's Creative Commons licence, unless indicated otherwise in a credit line to the material. If material is not included in the article's Creative Commons licence and your intended use is not permitted by statutory regulation or exceeds the permitted use, you will need to obtain permission directly from the copyright holder. To view a copy of this licence, visit http://creativecommons.org/licenses/by/4.0/.

\section{References}

Barr, W. A. (2017). Bovid locomotor functional trait distributions reflect land cover and annual precipitation in sub-Saharan Africa. Evolutionary Ecology Research, 18, 253-269.

Camazine, S., Deneubourg, J. L., Franks, N. R., Sneyd, J., Theraula, G. \& Bonabeau, E. (2003). Self-Organization in Biological Systems (Princeton studies in complexity). Second Printing Edition. Princeton University Press.

Conradi, T., Meerbeek, K. van., Ordonez, A., \& Svenning, J. C. (2020). Biogeographic historical legacies in the net primary productivity of Northern Hemisphere forests. Ecology Letters, 23(5), 800-810.

Darwin, C. (1958). In N. Barlow (Ed.) The Autobiography of Charles Darwin 1809-1882. With the original omissions restored. London: Collins. http://darwin-online.org.uk/content/frameset?viewtype= text\&itemID=F1497\&pageseq=1. Accessed 28 Sept 2013.

Darwin, C. (1859). On the origin of species by means of natural selection, or the preservation of favoured races in the struggle for life. London: John Murray. [1st edition] Online: http://darwin-online. org.uk. Accessed 7 Oct 2020.

Ekeland, I. (2000). Le mellieur des mondes possible. Mathématique et destinée. Science ouverte.

Evans, A., \& Sanson, G. (2003). The tooth of perfection: Functional and spatial constraints on mammalian tooth shape. Biological Journal of the Linnean Society, 78, 173-191.

Feynman, R. (1942). The principle of least action in quantum mechanics. $\mathrm{PhD}$ Thesis, Princeton University.
Fortelius, M., Eronen, J., Jernvall, J., Liu, L., Pushkina, D., Rinne, J., Tesakov, A., \& Vislobokova, I. (2002). Fossil mammals resolve regional patterns of Eurasian climate change over 20 million years. Evolutionary Ecology Research, 4, 1005-1016.

Galbrun, E., Tang, H., Fortelius, M., \& Zliobaite, I. (2018). Computational biomes: The ecometrics of large mammal teeth. Paleontologia Electronica, 21(1), 3A.

Gilbert, S. F., \& Tauber, A. I. (2016). Rethinking individuality: The dialectics of the holobiont. Biology and Philosophy, 31(6), 839-853.

Kropotkin, P. A. (1902). Mutual aid: A factor of evolution. London: Project Gutenberg e-text https://www.gutenberg.org/ebooks/4341. Accessed 7 Oct 2020.

Latham, R. (Ed.). (1985). The shorter Pepys. London: The Folio Society.

Leibniz, G. W. (1875-90). Die Philosophischen Schriften von Gottfried Wilhelm Leibniz, 7 vols. Gerhardt, C. I. (Ed.). Berlin: Weidemann.

Leibniz, G. W. (1948). Textes inédits d'après les manuscrits de la Bibliothèque provinciale de Hanovre. G. Grua (Ed.). Paris: Presses Universitaires de France.

Leibniz, G. W. (1989a). Philosophical papers and letters. L. E. Loemker (Ed.). Dordrecht: Kluwer.

Leibniz, G. W. (1989b). Philosophical essays. R. Ariew \& D. Garber (Eds.). Indianapolis: Hackett.

Leibniz, G. W. (2006). The shorter Leibniz texts: A collection of new translations. L. Strickland (Ed.). London: Continuum.

Liu, L., Puolamäki, K., Eronen, J. T., Ataabadi, M. M., Hernesniemi, E., \& Fortelius, M. (2012). Dental functional traits of mammals resolve productivity in terrestrial ecosystems past and present. Proceedings of the Royal Society B: Biological Sciences, 279, 2793-2799.

Margulis, L., \& Fester, R. (1991). Symbiosis as a source of evolutionary innovation: Specialization and morphogenesis. Cambridge: MIT Press.

Mason, M. K. (2019). Kropotkin and his theory of mutual aid. http:// www.moyak.com/papers/peter-kropotkin.html. Accessed 7 Oct 2020.

Matthews, B., De Meester, L., Jones, C. G., Ibelings, B. W., Bouma, T. J., Nuutinen, V., et al. (2014). Under niche construction: An operational bridge between ecology, evolution, and ecosystem science. Ecological Monographs, 84(2), 245-263.

McDonough, J. K. (2018). Optics. In M. R. Antognazza (Ed.), The Oxford handbook of Leibniz (pp. 425-437). Oxford: Oxford University Press.

Mosbrugger, V. (2009). Nearest-living-relative method. In V. Gornitz (Ed.), Encyclopedia of paleoclimatology and ancient environments (pp. 607-609). Dordrecht: Springer.

Mosbrugger, V., \& Utescher, T. (1997). The coexistence approach — A method for quantitative reconstructions of Tertiary terrestrial palaeoclimate data using plant fossils. Palaeogeography, Palaeoclimatology, Palaeoecology, 134(1-4), 61-86.

Phemister, P. (2005). Leibniz and the natural world: Activity, passivity and corporeal substances in Leibniz's philosophy. Dordrecht: Springer.

Roinila, M. (2007). Leibniz on rational decision-making. PhD dissertation. University of Helsinki: Helsinki.

Rudwick, M. J. S. (1976). The meaning of fossils. New York: Science History Publications.

Rutherford, D. (1995). Leibniz and the rational order of nature. Cambridge: Cambridge University Press.

Smith, J. E. H. (2011). Divine machines: Leibniz and the sciences of life. Princeton: Princeton University Press.

Spicer, R. A., Valdes, P. J., Spicer, T. E. V., Craggs, H. J., Srivastava, G., Mehrotra, R. C., \& Yang, J. (2009). New developments in CLAMP: Calibration using global gridded meteorological data. 
Palaeogeography, Palaeoclimatology, Palaeoecology, 283, 9198.

van Valen, L. (1973). A new evolutionary law. Evolutionary Theory, 1, $1-30$.

van Valen, L. (1980). Evolution as a zero-sum game for energy. Evolutionary Theory, 4, 289-300.

Voltaire (1759). Candide. Boni and Liveright, inc, New York, 1918. Project Gutenberg Ebook 19942. https://www.gutenberg.org/ ebooks/19942. Accessed 7 Oct 2020.
Wolfe, J. A. (1995). Paleoclimatic estimates from Tertiary leaf assemblages. Annual Review of Earth and Planetary Sciences, 23, 119142.

Publisher's note Springer Nature remains neutral with regard to jurisdictional claims in published maps and institutional affiliations. 